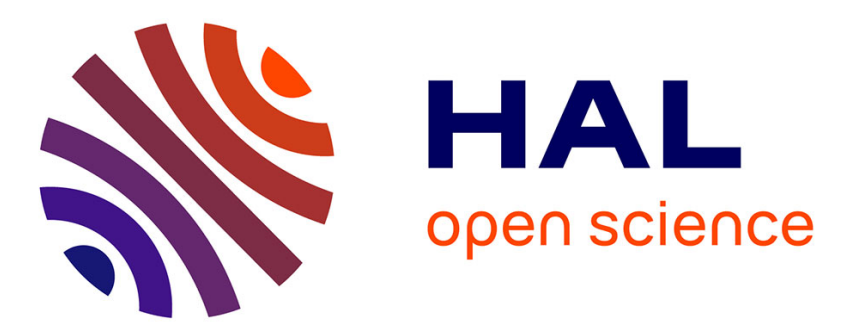

\title{
Lipase-catalyzed regioselective monoacetylation of unsymmetrical 1,5-primary diols
}

Camille Oger, Zsuzsanna Marton, Yasmin Brinkmann, Valérie Bultel-Poncé, Thierry Durand, Marianne Graber, Jean-Marie Galano

\section{- To cite this version:}

Camille Oger, Zsuzsanna Marton, Yasmin Brinkmann, Valérie Bultel-Poncé, Thierry Durand, et al.. Lipase-catalyzed regioselective monoacetylation of unsymmetrical 1,5-primary diols. Journal of Organic Chemistry, 2010, 75, pp.1892-1897. 10.1021/jo902541c . hal-00647807

\section{HAL Id: hal-00647807 \\ https://hal.science/hal-00647807}

Submitted on 2 Dec 2011

HAL is a multi-disciplinary open access archive for the deposit and dissemination of scientific research documents, whether they are published or not. The documents may come from teaching and research institutions in France or abroad, or from public or private research centers.
L'archive ouverte pluridisciplinaire HAL, est destinée au dépôt et à la diffusion de documents scientifiques de niveau recherche, publiés ou non, émanant des établissements d'enseignement et de recherche français ou étrangers, des laboratoires publics ou privés. 


\section{Lipase-catalyzed regioselective monoacetylation of unsymmetrical 1,5-primary diols}

Camille Oger ${ }^{\dagger}$, Zsuzsanna Marton ${ }^{\ddagger}$, Yasmin Brinkmann ${ }^{\dagger}$, Valérie Bultel-Poncé ${ }^{\dagger}$, Thierry Durand ${ }^{\dagger}$, Marianne Graber ${ }^{\ddagger}$, Jean-Marie Galano ${ }^{\dagger *}$

${ }^{\dagger}$ Institut des Biomolécules Max Mousseron (IBMM), UMR 5247 CNRS, Université Montpellier I et II, Faculté de Pharmacie, 15 avenue Charles Flahault, BP 14491, 34093 Montpellier, Cedex 05, France.

* Université de la Rochelle, Pôle Sciences-Bât. Marie Curie, UMR 6250 LIENSS CNRS-ULR, Avenue Michel Crépeau, 17042 La Rochelle, Cedex 01, France.

jgalano@univ-montpl.fr

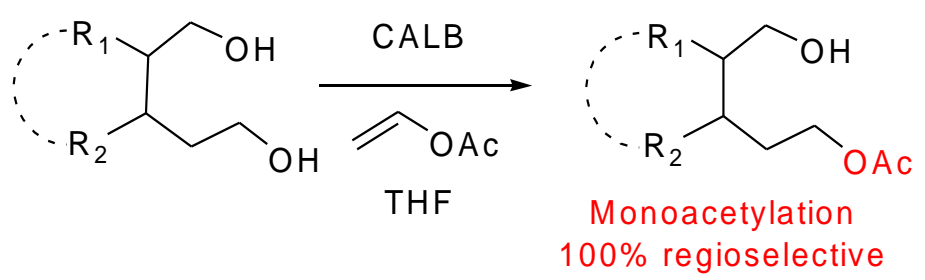

Lipase B from Candida antarctica (CALB) has been selected as the most suitable enzyme to catalyze the regioselective monoacetylation of 1,5-diol isoprostane intermediate, using vinyl acetate as an acyl transfer reagent in THF. We next applied this reaction on linear 2-substituted; 2,2'-disubstituted-1,5pentanediols and cyclic 2,3-disubstituted-1,5-pentanediols. To rationalize the regioselectivity observed, molecular docking simulations were performed. 


\section{Introduction}

The selective monoprotection of two chemically equivalent primary hydroxyl groups constitutes a challenge in organic chemistry. ${ }^{1}$ Protection of such compounds by chemical methods usually generates a mixture of unreacted, mono- and diprotected diols. Recently, P.A Clarke described monoacylation of meso- 1,3 and 1,4-diols, using cerium or ytterbium with modest regioselectivity. ${ }^{2}$ The development of enzymatic protecting group techniques offers viable alternatives to classical chemical approaches. However, enzymatic protection techniques of hydroxyl groups was mainly developed on polyhydroxylated compounds such as mono- and oligosaccharides ${ }^{3}$ and nucleosides, ${ }^{4}$ and therefore rarely applied to primary alcohols differentiation. ${ }^{5}$ To the best of our knowledge, there is only one example for the selective monoprotection of primary non-meso 1,5-diols being furthermore enzymatic. Indeed, in 2003 Santaniello et al. reported the monobenzoylation of the 2-methyl-1,5-pentanediol 1a (Scheme 1) using the Mucor miehei lipase (MML) and vinyl benzoate (VB) as an acyl transfer agent. ${ }^{6}$ The monobenzoylated compound $\mathbf{1 b}$ and its regioisomer $\mathbf{1 c}$ were obtained in a 85/15 ratio.

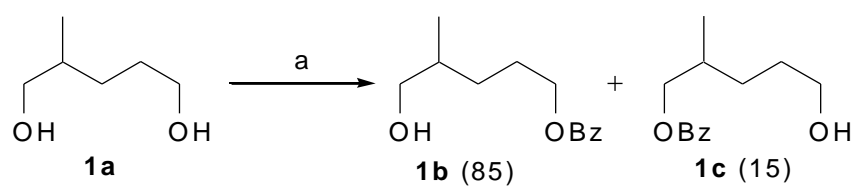

Scheme 1 Lipase-catalyzed monobenzoylation of 1,5-diol developed by Santaniello et al. Reagents: (a) MML, VB, tert-butyl methyl ether.

We recently developed a new strategy ${ }^{7}$ towards the isoprostanes synthesis including a selective oxidation of $2 \mathbf{a}$ using an iridium catalyst, ${ }^{8}$ which allowed the introduction of the $\alpha$ chain (Scheme 2). A method which could differentiate the two primary alcohol groups of the cyclic 2,3-disubstituted-1,5pentanediol key intermediate 2a would afford a complementary and more flexible strategy for the introduction of lateral chains. 

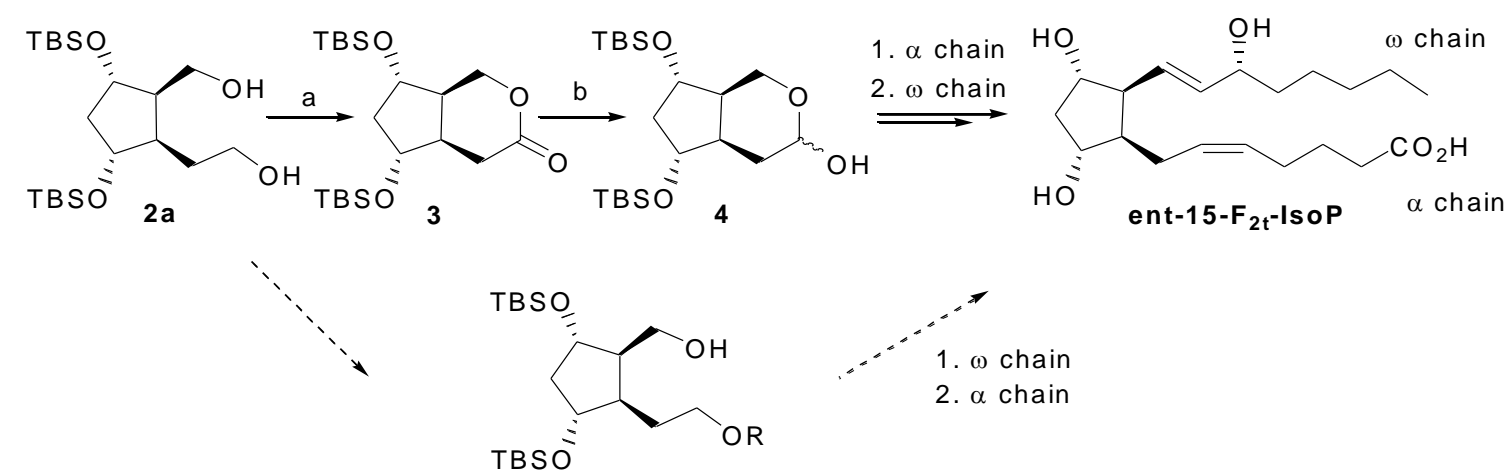

Scheme 2: Functionalization of 2a-1,5-diol: (a) $\mathrm{Cp}^{*} \operatorname{Ir}\left[\mathrm{OCH}_{2} \mathrm{C}\left(\mathrm{C}_{2} \mathrm{H}_{5}\right)_{2} \mathrm{NH}\right] 0.8$ mol\%, butanone, reflux, 91\%; (b) DIBAL-H, $\mathrm{CH}_{2} \mathrm{Cl}_{2},-78^{\circ} \mathrm{C}, 89 \%$.

\section{Results and discussion}

We started our investigation by using a slight modification of the Santaniello et al. reaction conditions for the regioselective monoprotection of the diol $\mathbf{2 a}$, employing vinyl acetate instead of vinyl benzoate

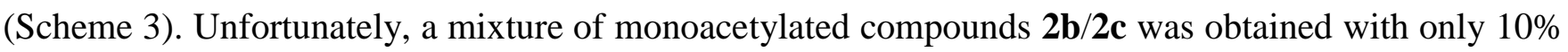
conversion (Table 1, entry 1).

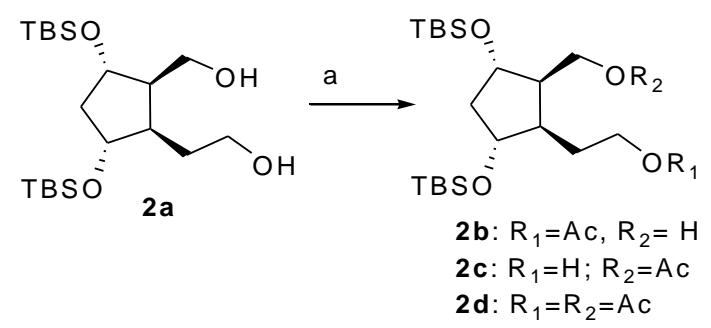

Scheme 3: (a) lipase, vinyl acetate, solvent.

We then decided to screen various enzymes in order to study the regioselective monoacetylation of the diol 2a. The results obtained are summarized in Table 1. No reaction occurs with the lipases from Pseudomonas cepacia (PCL), Amano AK, porcine pancreas (PPL) and Candida rugosa (entries 2-5). To our delight, full conversion and high regioselective monoprotection of $\mathbf{2 a}$ (entry 6) were obtained, when the lipase B from Candida antarctica (CALB) was used. The desired monoacetylated compound $\mathbf{2 b}$ was 
obtained as a sole product after $16 \mathrm{~h}$ in THF. We then studied the effect of vinyl acetate concentration with the aim to decrease the reaction time. Switching the ratio of solvent/vinyl acetate from $220 / 1$ to $1 / 1$ (v/v) still provided full conversion and a high regioselectivity with significantly reduced reaction time (entry 7). Similar result in term of reaction rate was obtained when the reaction was carried out in neat vinyl acetate or $t$ BuOMe albeit with a lower regioselectivity (90/10) (entries 8-9). ${ }^{9}$ Finally, other solvents such as diethyl ether or dichloromethane did not improve the regiochemical outcome of the reaction (entries 9-11). It is important to note that similar results were obtained with the racemic form of diol 2a, and that no enantioselective discrimination was observed.

Table 1: Lipase-catalyzed acetylation of 2a in different solvents.

\begin{tabular}{|c|c|c|c|c|c|}
\hline Entry & Enzymes & Solvent (solvent, vinyl acetate) & Time (h) & Ratio $\mathbf{2 b / 2 c / 2 d}$ & Yield $^{\mathrm{d}}(\%)$ \\
\hline 1 & $\mathrm{MML}^{\mathrm{a}}$ & $t$ BuOMe $(220: 1)$ & 16 & $90 / 10 / 0$ & $49^{\mathrm{e}}$ \\
\hline 2 & Amano $\mathrm{AK}^{\mathrm{a}}$ & $t \mathrm{BuOMe}(220: 1)$ & 16 & - & - \\
\hline 3 & $\mathrm{PCL}^{\mathrm{a}}$ & $t \mathrm{BuOMe}(220: 1)$ & 16 & - & - \\
\hline 4 & $\mathrm{PPL}^{\mathrm{a}}$ & $t \mathrm{BuOMe}(220: 1)$ & 16 & - & - \\
\hline 5 & Candida rugosa ${ }^{\mathrm{a}}$ & $t \mathrm{BuOMe}(220: 1)$ & 16 & $70 / 30 / 0$ & $31^{\mathrm{e}}$ \\
\hline 6 & CALB $^{\mathrm{a}}$ & THF (220:1) & 16 & $100 / 0 / 0$ & 96 \\
\hline 7 & CALB $^{b}$ & THF (1:1) & 8 & $100 / 0 / 0$ & 98 \\
\hline 8 & CALB $^{b}$ & Vinyl acetate & 8 & $90 / 0 / 10$ & 90 \\
\hline 9 & CALB $^{\mathrm{b}}$ & $t \operatorname{BuOMe}(1: 1)$ & 6 & $90 / 0 / 10$ & 82 \\
\hline 10 & $\mathrm{CALB}^{\mathrm{b}}$ & $\mathrm{CH}_{2} \mathrm{Cl}_{2}(1: 1)$ & 8 & $100 / 0 / 0^{c}$ & 97 \\
\hline 11 & CALB $^{b}$ & $\mathrm{Et}_{2} \mathrm{O}(1: 1)$ & 12 & $100 / 0 / 0^{c}$ & 97 \\
\hline
\end{tabular}

(a) $50 \mathrm{mg}$ of $\mathbf{2 a}, 10 \mathrm{mg}$ of enzyme in $3 \mathrm{~mL}$ of solvent and $15 \mu \mathrm{L}$ of vinyl acetate; (b) $100 \mathrm{mg}$ of $\mathbf{2 a}, 30$ mg of CALB in $10 \mathrm{~mL}$ of a mixture solvent/ vinyl acetate (1/1); (c) diacetylated compound 2d was not 
detected by ${ }^{1} \mathrm{H}$ NMR of the crude reaction but traces were separated by column chromatography; (d) Yields refer to monoacetylated compounds isolated after flash chromatography; e) reaction was stopped after $16 \mathrm{~h}$ when unsatisfied ratio was observed by TLC.

With these results in hand, we sought to examine the scope of the method. The above optimized conditions were then applied to an array of cyclic 2,3-disubstituted-1,5-pentanediols (compounds 5a to 13a, Figure 1).
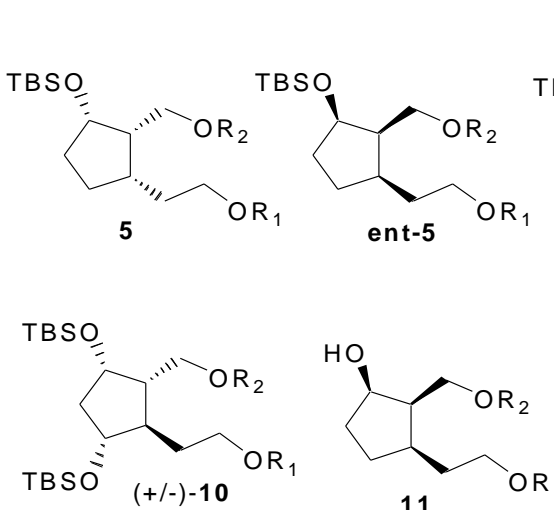
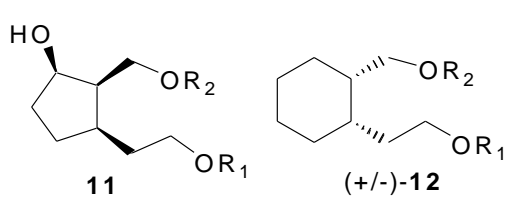

$(+/-)-12$
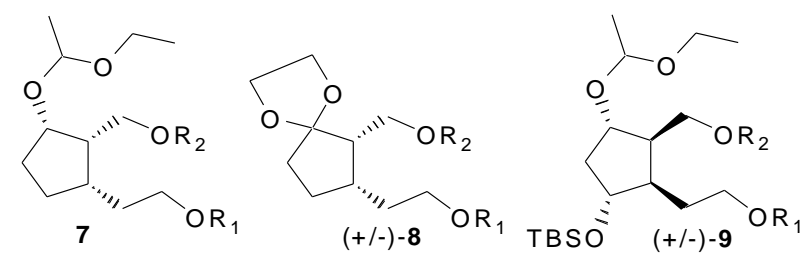

$(+/-)-8 \mathrm{OR}_{1}$ TBSO

5-13a: $\mathrm{R}_{1}=\mathrm{R}_{2}=\mathrm{H}$ 5-13b: $R_{1}=A c ; R_{2}=H$ 5-13c: $R_{1}=H ; R_{2}=A c$ 5-13d: $R_{1}=R_{2}=A c$

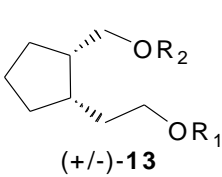

$(+/-)-13$

Figure 1: Structure of 2,3-disubstituted 1,5-diols and their acetates (compounds 5a-d to 13a-d).

The results are summarized in Table 2. In all cases full conversion was obtained. For isoprostanes precursors (5a-8a), a complete regioselectivity in favor of monoacetylated compounds $\mathbf{5 b - 8 b}$ (entries 15) were obtained, whereas 3\% of bis-acetylated compound 9d was observed with 9a-diol (entry 6). Compound 10a, a prostaglandins precursor, gave a similar result providing exclusively the desired monoprotected compound 10b (entry 7). Surprisingly, only the bis-protected compound 11d was obtained when the reaction was run with the hydroxylpentan-1,5-diol 11a (entry 8). Poor results were obtained with the naked cyclohexane 12a (entry 9) with a ratio bis-acetylated compound 12d / monoacetylated product 12b of 66/34. Finally, cyclopentane derivatives 13a (entry 10) gave only the bisacetylated adduct $\mathbf{1 3 d}$. It should be noted that the reaction could be run on gram scale on diols $\mathbf{2 a}, \mathbf{5 a}-\mathbf{9 a}$, with high yields (96-100\%) and no loss of regioselectivity. 
Table 2: CALB-catalyzed acetylation of diols (5a-13a).

\begin{tabular}{|c|c|c|c|c|c|}
\hline Entry & Diol $^{\mathrm{a}}$ & $\begin{array}{c}\text { Time } \\
\text { (h) }\end{array}$ & Products & $\begin{array}{l}\text { Ratio }^{b} \\
\text { b/c/d }\end{array}$ & $\begin{array}{c}\text { Yield }^{\mathrm{c}} \\
(\%)\end{array}$ \\
\hline 1 & $5 \mathbf{a}$ & 2 & $5 b$ & $100 / 0 / 0$ & 88 \\
\hline 2 & $\begin{array}{l}\text { ent- } \\
5 \mathbf{a}\end{array}$ & 2 & ent-5b & $100 / 0 / 0$ & 88 \\
\hline 3 & $6 \mathbf{a}$ & 2 & $6 b$ & $100 / 0 / 0$ & 88 \\
\hline 4 & $7 \mathbf{a}$ & 2 & $7 b$ & $100 / 0 / 0$ & 83 \\
\hline 5 & $8 \mathbf{a}$ & 2 & $8 b$ & $100 / 0 / 0$ & 94 \\
\hline 6 & $9 \mathbf{a}$ & 23 & $9 b / 9 d$ & $97 / 0 / 3$ & 97 \\
\hline 7 & $10 \mathrm{a}$ & 24 & $10 b$ & $100 / 0 / 0$ & 90 \\
\hline 8 & $11 a$ & 2 & 11d & 0/0/100 & - \\
\hline 9 & $12 a$ & 3.5 & $12 b / 12 d$ & $34 / 0 / 66$ & 25 \\
\hline 10 & $13 \mathbf{a}$ & 24 & 13d & $0 / 0 / 100$ & - \\
\hline
\end{tabular}

(a) $100 \mathrm{mg}$ of diol; $30 \mathrm{mg}$ of CALB in $10 \mathrm{~mL}$ of a mixture THF/ vinyl acetate (1/1); (b) Determined by ${ }^{1} \mathrm{H}$ NMR analysis of the crude reaction at full conversion; (c) Yields refer to monoacetylated compound isolated after flash chromatography.

Encouraged by the above results and to further extend the scope of the reaction, we applied our optimized conditions to several linear 2-substituted diols (14a-17a,Figure 2). In all cases, regioselectivities observed were lower than those obtained for cyclic 2,3-disubstituted-1,5-pentane-diols compounds. Good results were obtained for compounds $\mathbf{1 4 a}$ and $\mathbf{1 5 a}$ with $79 \%$ yields in favor of the 
monoprotected compounds $\mathbf{1 4 b}$ and $\mathbf{1 5 b}$ (entries 1 and 2, Table 3). But, as observed for cyclic diol 11a, the presence of a free hydroxyl group seems to have a deleterious effect on the regioselectivity.

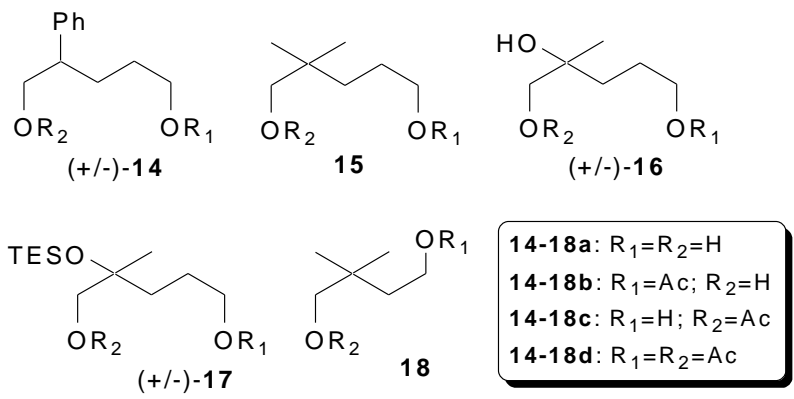

Figure 2: Structure of linear 2-substituted and 2,2'-substituted 1,5-diols and their acetates analogs (compounds 14a-d to 17a-d).

Indeed, acetylation of compound 16a bearing a free tertiary hydroxyl group produced exclusively the bis-acetylated product $\mathbf{1 6 d}$ whereas reaction of its silylated version (compound 17a) gave a mixture of mono and diacetate adducts (entries 3 and 4). Finally, as observed with the 1,5-diol 15a, good regioselectivity was obtained for the 1,4-diol-18a, with $66 \%$ yield in favor of the monoacetylated compound 18b. For all the substrates presented, mono-protected compounds 2c-17c were never observed. The reaction was completely regioselective towards the alcohol with the longer chain. 
Table 3: CALB-catalyzed acetylation of diols (14a-17a).

\begin{tabular}{|c|c|c|c|c|c|}
\hline \multirow[b]{2}{*}{ Entry } & \multicolumn{3}{|c|}{ Time } & \multirow{2}{*}{$\begin{array}{l}\text { Ratio }^{b} \\
\text { b/c/d }\end{array}$} & \multirow{2}{*}{$\begin{array}{c}\text { Yield }^{\circ} \\
(\%)\end{array}$} \\
\hline & Diol $^{\mathrm{a}}$ & (h) & Products & & \\
\hline 1 & $14 a$ & 1 & $14 b / 14 d$ & $87 / 0 / 13$ & 79 \\
\hline 2 & $15 \mathbf{a}$ & 42 & $15 b / 15 d$ & $78 / 0 / 22$ & 78 \\
\hline 3 & $16 \mathbf{a}$ & 0.5 & 16d & $0 / 0 / 100$ & - \\
\hline 4 & $17 \mathbf{a}$ & 3 & $17 b / 17 d$ & $36 / 0 / 64$ & 30 \\
\hline 5 & $18 \mathbf{a}$ & 3 & $18 b / 18 d$ & $90 / 0 / 10$ & 66 \\
\hline
\end{tabular}

(a) $100 \mathrm{mg}$ of diol; $30 \mathrm{mg}$ of CALB in $10 \mathrm{~mL}$ of a mixture THF/ vinyl acetate (1/1); (b) Determined by ${ }^{1} \mathrm{H}$ NMR analysis of the crude reaction at full conversion; (c) Yields refer to monoacetylated product isolated after flash chromatography.

\section{Molecular Modeling Study}

Recently, computer-based modeling methodology has been used to understand the regioselectivity in acylation of complex substrate including several hydroxyl groups catalyzed by enzymes. ${ }^{10}$ In order to explain the regioselectivity obtained with the same enzyme during our study, docking simulations were performed on five substrates: with good regioselectivities (5a, ent-5a and 6a: Figure 3), modest regioselectivity (15a: Figure 3) and without selectivity (11a: Figure 3). 

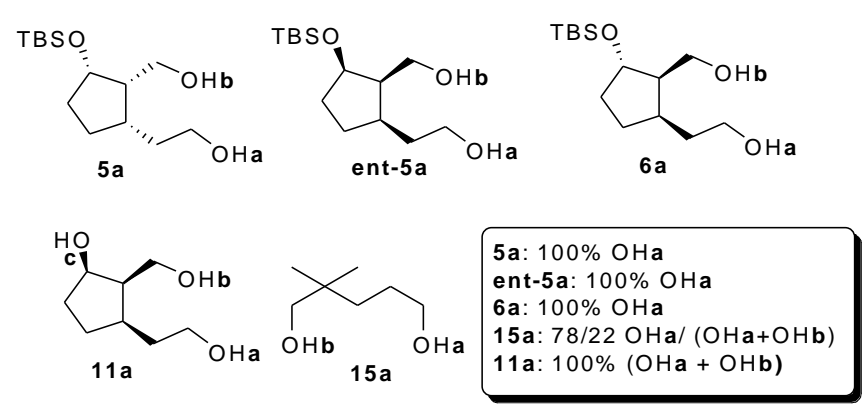

Figure 3: Structure of the docked 1,5-diols and summary of the regioselectivities observed.

Molecular docking experiments of compounds 5a, ent-5a, 6a, 11a and 15a into the active site of the CALB were performed using a CHARMm force field ${ }^{11}$ based docking tool: CDOCKER ${ }^{12}$ of Discovery Studio 2.1 (Accelrys Inc., San Diego, CA). The study was composed of the following steps: preparation of the starting enzyme structure and modeling of the acetyl-enzyme; docking of the 1,5-primary diols substrates; scoring; optimization and structural analysis of the best poses; verification of the reliability of the final models. After scoring, poses with a good consensus score and with a good orientation of the hydroxyl groups towards the active site were retained and were submitted to further optimizations. Three criteria have to be combined for the complex to be considered as a productive binding mode, in order to conclude the acetylation reaction is able to take place. First, the root mean square deviation (rmsd) value between the initial crystal structure and the final optimized structure must be small. As found by Valliki et al. for prostaglandins acetylation, a rmsd value $<3 \AA$ was chosen, as a limit. ${ }^{13}$ Then, the complex must form minimum two of the three hydrogen bond interactions between the acetate oxygen and the hydrogen of the Thr40 and Gln106 residues. Finally, the hydroxyl group of the 1,5-diol must be placed simultaneously at lower than $4 \AA$ from the $\mathrm{sp}^{2}$ carbon of the acetyl and the $\mathrm{N} \varepsilon$ atom of His224 to be considered as a productive complex (Scheme 4). 


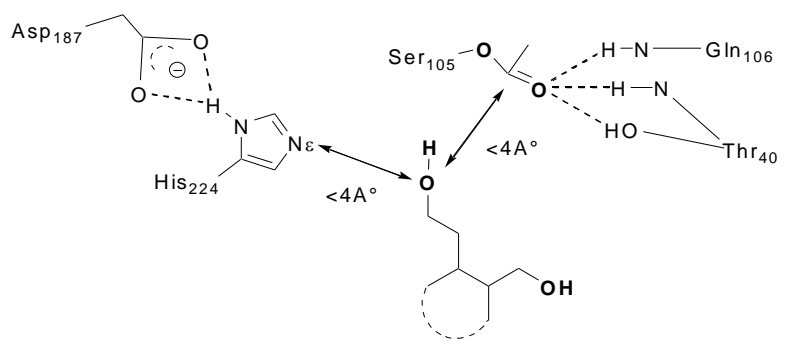

Scheme 4: Structural requirements the substrate must satisfy to be considered as reactive.

In Table 4 are summarized the transacetylation distances for structures having the best potential energy after optimizations, for the diols $\mathbf{5 a}$ and its enantiomer, $\mathbf{6 a}$ and $\mathbf{1 5 a}$.

Table 4: Distances between the hydroxyl group, the acetate carbonyl and the His224-N $\varepsilon$ atom, after optimization for diols 5a, ent-5a, 6a and 15a.

\begin{tabular}{|c|c|c|c|c|}
\hline Entry & Complex & Buried $\mathrm{OH}$ & Distance from ACE $(\AA)$ & Distance from His224 $(\AA)$ \\
\hline \multirow[t]{2}{*}{1} & 5a-I & $\mathrm{OHa}$ & 3.3 & 3.7 \\
\hline & & $\mathrm{OHb}$ & 6.5 & 6.0 \\
\hline \multirow[t]{2}{*}{2} & 5a-II & $\mathrm{OHa}$ & 3.5 & 3.3 \\
\hline & & $\mathrm{OHb}$ & 7.9 & 7.0 \\
\hline \multirow[t]{2}{*}{3} & ent-5a-I & $\mathrm{OHa}$ & 3.7 & 3.0 \\
\hline & & $\mathrm{OHb}$ & 6.6 & 8.1 \\
\hline \multirow[t]{2}{*}{4} & ent-5a-II & $\mathrm{OHa}$ & 3.8 & 3.1 \\
\hline & & $\mathrm{OHb}$ & 4.6 & 5.8 \\
\hline \multirow[t]{2}{*}{5} & 6a-I & $\mathrm{OHa}$ & 3.3 & 3.8 \\
\hline & & $\mathrm{OHb}$ & 4.4 & 5.8 \\
\hline 6 & 6a-II & $\mathrm{OHa}$ & 3.4 & 3.8 \\
\hline
\end{tabular}




\begin{tabular}{lcccc}
\hline & & OHb & 6.5 & 7.6 \\
7 & 15a-I & OHa & $\mathbf{3 . 4}$ & $\mathbf{4 . 1}$ \\
& & OHb & 5.8 & 7.6 \\
& 15a-II & OHa & $\mathbf{3 . 9}$ & $\mathbf{4 . 4}$ \\
& & OHb & 5.8 & 7.6 \\
\hline
\end{tabular}

In all cases, the different complexes obtained with diols 5a, ent-5a and 6a (entries 1-6, Table 4) adopted the acetylation distances criterion, with distances between the OHa hydroxyl, the acetate carbon and the His224: N $\varepsilon$ nitrogen lower than $4 \AA$. For the diol 15a (entries 7 and 8), the distance between the hydroxyl group OHa and the His224: $\mathrm{N} \varepsilon$ nitrogen is slightly larger than the fixed criteria. However, OHb hydroxyl is too far from the catalytic residues with distances from 4.4 to $7.9 \AA$. The superimposition of the protein structure in the complex and the crystal structure showed minor displacements ( $r m s d$ values about $0.7 \AA$ ). Finally, two hydrogen bond interactions between oxyanion hole residues and OHa were formed for each complex.

The docking experiments of diols 5a, ent-5a, 6a and 15a showed that substrates are preferentially orientated to form productive complexes with the OHa hydroxyl rather than the OHb (Figure 4). Those results are in accordance with the experimental acetylation of the OHa hydroxyl. 


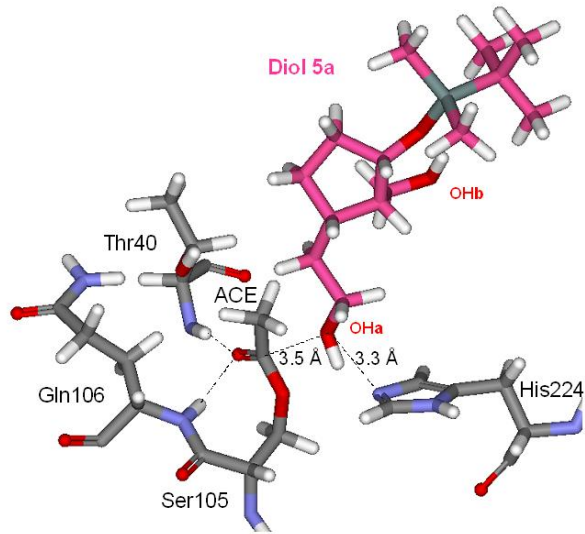

b)

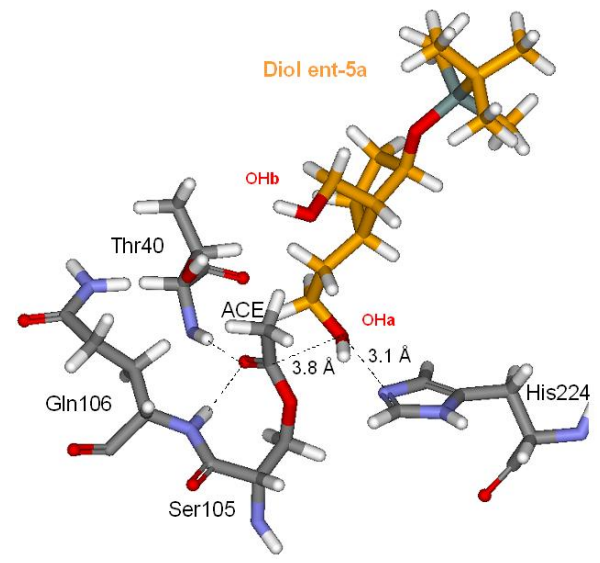

c)

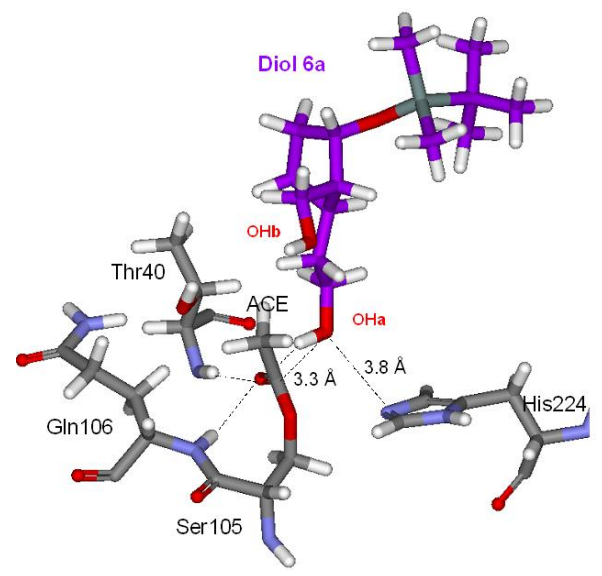




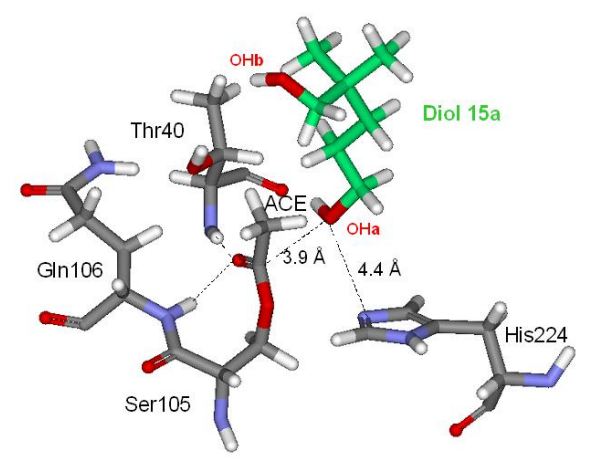

Figure 4: Orientations and hydrogen bond interactions (dashed lines) of the best structures obtained with diols: a) 5a (pink); b) ent-5a (orange); c) 6a (purple) and d) 15a (green). For clarity, only the residues useful for discussion are shown (grey).

Encouraged by the above results, we applied this docking procedure to the diol 11a. In this case, both hydroxyl $\mathrm{OHa}$ and $\mathrm{OHb}$ were acetylated during the chemistry procedure, to form the bis-acetylated compound 11d. Our first investigation led us to consider an effect of the free alcohol OHc even though the mechanism of this contribution is presently unclear. In $50 \%$ of the poses obtained after the docking experiment, the OHa hydroxyl was orientated in order to form a productive binding mode with the catalytic site, and the other $50 \%$ were orientated towards the OHb hydroxyl. After optimization, four complexes were then retained: two in favor of $\mathrm{OHa}$ and two in favor of $\mathrm{OHb}$ (Table 5).

Table 5: Distances between the hydroxyl group, the acetate carbonyl and the His224-Ne atom, after optimization for the diol 11a.

\begin{tabular}{cccc}
\hline & & & Distance \\
Entry Complex & & Distance & from ACE \\
& OH & $(\AA)$ & His224 \\
& & & $(\AA)$ \\
& & & \\
\hline
\end{tabular}




\begin{tabular}{|c|c|c|c|c|}
\hline \multirow[t]{2}{*}{1} & 11a-I & $\mathrm{OHa}$ & 5.7 & 4.8 \\
\hline & & $\mathrm{OHb}$ & 3.2 & 3.9 \\
\hline \multirow[t]{2}{*}{2} & 11a-II & $\mathrm{OHa}$ & 7.6 & 7.0 \\
\hline & & $\mathrm{OHb}$ & 3.2 & 3.8 \\
\hline \multirow[t]{2}{*}{3} & 11a-III & $\mathrm{OHa}$ & 4.1 & 4.3 \\
\hline & & $\mathrm{OHb}$ & 7.1 & 8.7 \\
\hline \multirow[t]{2}{*}{4} & 11a-IV & $\mathrm{OHa}$ & 3.9 & 4.1 \\
\hline & & $\mathrm{OHb}$ & 9.2 & 9.2 \\
\hline
\end{tabular}

The results summarized in Table 5 hold with those aforementioned and tend to corroborate the experience. Indeed, complexes 11a-I and 11a-II are able to form productive binding modes with the OHb alcohol (entries 1 and 2). Acetylating distances OHb-ACE and OHb- His224:N $\varepsilon$ fit the distance criterion. In the same way, productive binding modes are formed with the $\mathrm{OHa}$ alcohol in complexes 11a-III and 11a-IV (entries 3 and 4) with distances OHa-ACE and OHa-His224:Ne close to $4 \AA$. In fact, diol 11a is able to form two productive binding modes with the active site of the CALB, in order to acetylate both hydroxyls.

To complete this study, one more docking experience was performed, replacing one hydroxyl with an acetate, to prove that a second acetylation reaction could be done thereafter. In Table 6 are summarized the results of the docking with monoacetylated products $\mathbf{1 1 b}$ and 11c. For these molecules, the free alcohol (OHb and $\mathrm{OHa}$ respectively) were orientated towards Ser105 and His224 residues. After optimizations, the distances between the non acetylated hydroxyl group $(\mathrm{OHa}$ or $\mathrm{OHb})$ and the acetate were lower than $4 \AA$. The distances between the $\mathrm{N} \varepsilon$ atom of His 224 and the same free alcohol were ranged from 4.4 to $4.8 \AA$. The two others criteria ( $r m s d$ value and at least two hydrogen bonds with the 
oxyanion hole) were also respected. This suggests that after a first acetylation reaction, the residual hydroxyl group (OHa or OHb) could be acetylated.

Table 6: Distances between the hydroxyl group, the acetate carbonyl and the His224-N $\varepsilon$ atom, after optimization for compounds $\mathbf{1 1 b}$ and 11c.

\begin{tabular}{ccccc}
\hline & & \multicolumn{3}{r}{ Distance } \\
Entry & Complex & Buried & from & from \\
& & OH & HCE $(\AA)$ & $(\AA)$ \\
& & & & 4.5 \\
\hline 1 & 11b-I & OHb & 3.3 & 4.4 \\
3 & 11b-1I & OHb & 3.2 & 4.8 \\
4 & 11c-I & OHa & 4.0 & 4.8 \\
\hline
\end{tabular}

It is important to note that after optimization, the secondary alcohol $(\mathrm{OHc})$ of the diol 11a was placed into the cavity of the enzyme. However, in the case of the diol 5a, where the same secondary alcohol was protected, the protecting group stands outside the cavity (Figure 5).

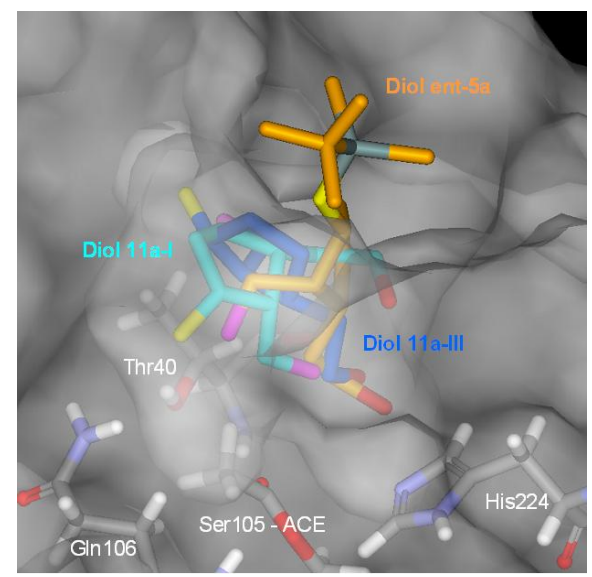


Figure 5: Orientations for diols 11a-I (cyan) and 11a-III (blue) compared to the protected diol 5a (orange). For clarity, only the residues useful for discussion are shown (grey). Connolly surface of the enzyme is represented in white. $\mathrm{OHb}$ in pink and $\mathrm{OHc}$ in yellow.

\section{Conclusion}

In conclusion, we have developed for the first time an highly regioselective monoacetylation of unsymmetrical 1,5-diols substituted at the $\mathrm{C}_{2}$ or $\mathrm{C}_{2} / \mathrm{C}_{3}$ carbons. This reaction, useful for the synthesis of isoprostanes derivatives could also be extended to other derivatives, as shown with linear structures.

Docking experiments were used to study CALB-catalyzed acetylation of four 1,5-diols and all the substrates tested were able to dock with the CALB active site, in order to produce reactive complexes. The docking results corroborate with the regioselectivities observed experimentally and lead to consider the use of docking experiments as a predictive tool.

\section{Experimental Section}

\section{General Procedure for Regioselective Enzymatic Acetylation}

To a solution of the diol (1a-17a, $100 \mathrm{mg})$, in $10 \mathrm{~mL}$ of a mixture THF/ vinyl acetate (1/1, v/v) was added the Candida antarctica lipase B (30 mg). The mixtures were stirred with a rotavapor and followed by TLC, during the appropriate time (see tables), then filtered, rinsed with diethyl ether and the solvents evaporated under reduced pressure. The ratio of acetates products was checked by NMR of the crude before purification by flash chromatography.

\section{Computational methods}


Molecular dynamics calculations and docking simulations were performed with CHARMm force field, using the 2.1 version of Discovery Studio (Accelrys Inc.). MD simulations were carried out by adopting a $12 \AA$ non-bound spherical cut-off, using the isothermal-isochoric ensemble (NVT) ${ }^{14}$ and with distancedependent dielectric implicit solvent model.

\section{Acknowledgments}

We thank the Ministère de l'Education Nationale et de la Recherche for a PhD fellowship (C.O). We are deeply grateful to Pr. Jean-Yves Lallemand and the ICSN for their generous financial support. A part of this work was also supported by a University Montpellier I grant (BQR-2008).

Supporting Information Available: Additional experimental details, NMR's data of all compounds and molecular dynamics calculations and docking simulations details are available free of charge via the Internet at http://pubs.acs.org.

\section{References}

1. Greene, T. W.; Wuts, P. G. M. Protective Groups in Organic Synthesis; Wiley: New York, 1991.

2. Clarke, P. A. Tetrahedron Lett. 2002, 43, 4761.

3. For seminal work see: (a) Riva, S.; Chopineau, J.; Kieboom, A. P. G.; Klibanov, A. M. J. Am. Chem. Soc. 1988, 110, 584, (b) Therisod, M.; Klibanov, A. M. J. Am. Chem. Soc. 1987, 109, 3977. (c) Hennen, W. J.; Sweers, H. M.; Wang, Y. F.; Wong, C. H. J. Org. Chem. 1988, 53, 4939. For a review on enzymatic protective group techniques, see: d) Kadereit, D.; Waldmann, H. Chem. Rev. 2001, 101, 3367. 
4. For seminal work see: (a) Wong, C. H.; Chen, S. T.; Hennen, W. J.; Bibbs, J. A.; Wang, Y. F.; Liu, J. L. C.; Pantoliano, M. W.; Whitlow, M.; Bryan, P. N. J. Am. Chem. Soc. 1990, 112, 945. (b) Moris, F.; Gotor, V. J. Org. Chem. 1992, 57, 2490.

5. For non-symmetric primary 1,3-diols see: (a) Hisano, T.; Onodera, K.; Toyabe, Y.; Mase, N.; Yoda, H.; Takabe, K. Tetrahedron Lett. 2005, 46, 6293. For primary 1,4-diols (acyclic $\alpha, \omega$,-terpenediols) see: (b) Takabe, K.; Mase, N.; Hisano, T.; Yoda, H. Tetrahedron Lett. 2003, 44, 3267.

6. Ciuffreda, P.; Casati, S.; Santaniello, E. Tetrahedron Lett. 2003, 44, 3663.

7. Oger, C.; Brinkmann, Y.; Bouazzaoui, S.; Durand, T. Galano, J.-M. Org. Lett. 2008, 10, 5087.

8. Suzuki, T.; Morita, K.; Tsuchida, M.; Hiroi, K. Org. Lett. 2002,4, 2361.

9. Solvent effects on enantioselectivities have been previously observed which could account for the lowering in regioselectivy, see: (a) Carrea, G.; D'Arrigo, P.; Piergianni, V.; Roncaglio, S.; Secundo, F.; Servi, S. Biochim. Biophys. Acta 1995, 1255, 273. (b) Wescott, C. R.; Klibanov, A. M. Biochim. Biophys. Acta 1994, 1206, 1.

10.(a) De Oliveira, E. B.; Humeau, C.; Chebil, L.; Maia, E. R.; Dehez ; F.; Maigret, B.; Ghoul, M.; Engasser, J.-M. J. Mol. Catal. B: Enzym. 2009, 59, 96. (b) Pieraccini, S.; Sironi, M.; Colombo, G. Chemical Physics Letters 2006, 418, 373-376.(c) Colombo, G.; Riva, S., Danieli; B. Tetrahedron 2004, 60, 741. (d) Fuentes, G.; Cruces, M. A.; Plou, F. J.; Ballesteros, A.; Verma, C. S. Chembiochem 2002, 3, 907. (e) Rich, J. O.; Bedell, B. A.; Dordick, J. S. Biotechnol. Bioeng. 1995, $45,426$.

11.MacKerell, J., A. D.; Bashford, D.; Bellott, M.; Dunbrack Jr., R. L.; Evanseck, J.; Field, M. J.; Fischer, S.; Gao, J.; Guo, H.; Ha, S.; Joseph, D.; Kuchnir, L.; Kuczera, K.; Lau, F. T. K.; Mattos, C.; Michnick, S.; Ngo, T.; Nguyen, D. T.; Prodhom, B.; Reiher, I., W. E.; Roux, B.; Schlenkrich, M.; Smith, J.; Stote, R.; Straub, J.; Watanabe, M.; Wiorkiewicz-Kuczera, J.; Yin, D.; Karplus, M. J. Phys. Chem. B. 1998, 102, 3586. 
12.Wu, G.; Robertson, D. H.; Brooks III, C.L.; Veith, M. J. Comput. Chem. 2003, 24, 1549.

13.Valliki, I.; Fransson, L.; Hult, K.; Järving, I.; Pehk, T.; Samel, N.; Tõugu, V.; Villo, O.; Parve, J. J. Mol. Catal. B: Enzym. 2005, 35, 62.

14.Berendsen, H. J. C.; Postma, J. P. M.; Van Gunsteren, W.F.; Dinola, A.; Haak, J. R. J. Chem. Phys. $198481,3684$. 